NASA/TM-2005-213640

\title{
Low Gravity Issues of Deep Space Refueling
}

\author{
David J. Chato
}

Glenn Research Center, Cleveland, Ohio 
Since its founding, NASA has been dedicated to the advancement of aeronautics and space science. The NASA Scientific and Technical Information (STI) Program Office plays a key part in helping NASA maintain this important role.

The NASA STI Program Office is operated by Langley Research Center, the Lead Center for NASA's scientific and technical information. The NASA STI Program Office provides access to the NASA STI Database, the largest collection of aeronautical and space science STI in the world. The Program Office is also NASA's institutional mechanism for disseminating the results of its research and development activities. These results are published by NASA in the NASA STI Report Series, which includes the following report types:

- TECHNICAL PUBLICATION. Reports of completed research or a major significant phase of research that present the results of NASA programs and include extensive data or theoretical analysis. Includes compilations of significant scientific and technical data and information deemed to be of continuing reference value. NASA's counterpart of peerreviewed formal professional papers but has less stringent limitations on manuscript length and extent of graphic presentations.

- TECHNICAL MEMORANDUM. Scientific and technical findings that are preliminary or of specialized interest, e.g., quick release reports, working papers, and bibliographies that contain minimal annotation. Does not contain extensive analysis.

- CONTRACTOR REPORT. Scientific and technical findings by NASA-sponsored contractors and grantees.
- CONFERENCE PUBLICATION. Collected papers from scientific and technical conferences, symposia, seminars, or other meetings sponsored or cosponsored by NASA.

- SPECIAL PUBLICATION. Scientific, technical, or historical information from NASA programs, projects, and missions, often concerned with subjects having substantial public interest.

- TECHNICAL TRANSLATION. Englishlanguage translations of foreign scientific and technical material pertinent to NASA's mission.

Specialized services that complement the STI Program Office's diverse offerings include creating custom thesauri, building customized databases, organizing and publishing research results ... even providing videos.

For more information about the NASA STI Program Office, see the following:

- Access the NASA STI Program Home Page at http://www.sti.nasa.gov

- E-mail your question via the Internet to help@sti.nasa.gov

- Fax your question to the NASA Access Help Desk at 301-621-0134

- Telephone the NASA Access Help Desk at 301-621-0390

- Write to:

NASA Access Help Desk

NASA Center for AeroSpace Information 7121 Standard Drive

Hanover, MD 21076 
NASA/TM-2005-213640

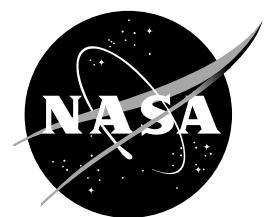

\section{Low Gravity Issues of Deep Space Refueling}

David J. Chato

Glenn Research Center, Cleveland, Ohio

Prepared for the

43rd Aerospace Sciences Meeting and Exhibit

sponsored by the American Institute of Aeronautics and Astronautics

Reno, Nevada, Janaury 10-13, 2005

National Aeronautics and

Space Administration

Glenn Research Center

July 2005 
Available from

NASA Center for Aerospace Information 7121 Standard Drive

Hanover, MD 21076
National Technical Information Service 5285 Port Royal Road Springfield, VA 22100

Available electronically at http://gltrs.grc.nasa.gov 


\title{
Low Gravity Issues of Deep Space Refueling
}

\author{
David J. Chato \\ National Aeronautics and Space Administration \\ Glenn Research Center \\ Cleveland, Ohio 44135
}

This paper discusses the technologies required to develop deep space refueling of cryogenic propellants and low cost flight experiments to develop them. Key technologies include long term storage, pressure control, mass gauging, liquid acquisition, and fluid transfer. Prior flight experiments used to mature technologies are discussed. A plan is presented to systematically study the deep space refueling problem and devise low-cost experiments to further mature technologies and prepare for full scale flight demonstrations.

\section{Introduction}

Deep space cryogenic refueling is a subject of great interest to many spacefarers. Effective human exploration of the solar system will require refueling in low gravity with large quantities of cryogenic propellants. Figure 1 shows an artist's concept of space refueling in low earth orbit. Effective use of Lunar-produced hydrogen and oxygen will require transfer of propellant at L1 or other locations outside Earth's gravity well. Although modest quantities of non-cryogenic propellant are transferred routinely, the unique properties of cryogens and the much larger quantities of required propellant make the prior techniques ineffective for deep space cryogenic refueling. ${ }^{1}$

Deep space cryogenic refueling allows the reuse of hardware already in orbit, thus reducing lift mass. Stages initially filled on-orbit can eliminate many of the systems and structural mass required to support and maintain cryogens on the launch pad. Transfer allows tanks on the mission vehicle to be insulated only for the mission rather than the months required to assemble a stage on-orbit. The valving and hardware for cryogenic transfer should be substantially simpler and safer than drop tank designs (two 4- to 6-inch disconnects that can be checked for leakage versus eight 17-inch Shuttle-ET style valves that must seal instantaneously when the pyrotechnic devices fire to drop the tanks). ${ }^{2}$

In recognition of the importance of deep space cryogenic refueling NASA has assembled a team of researchers to investigate technological issues of this system and propose experiments to advance the technology. NASA's Exploration Systems Research and Technology (ESR\&T) [formerly known as Human and Robotic Technology] Program has documented its research strategy for exploration in reference 32. The efforts detailed in this paper support three main areas in this research strategy; In-Space Technology Experiments, High Energy Space Systems and Power, Propulsion, and Chemical Systems. Most directly this research will offer the In-Space Technology Experiments Program designs for near-term, low-cost flight experiments to investigate low-g challenges of cryogenic refueling. These flight experiments support technology in both the High Energy Space Systems

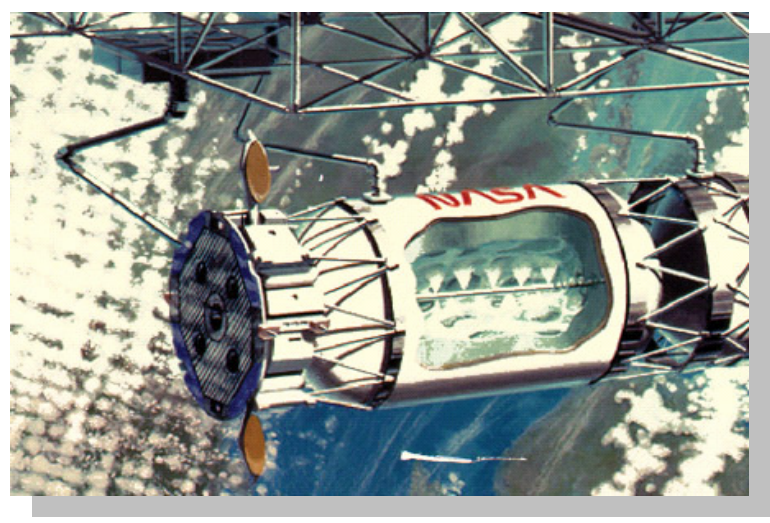

Figure 1.-Artist's concept of a space exploration stage being refueled from a depot in low earth orbit via no-vent fill. 
technology element (HESS) and the Power, Propulsion, and Chemical Systems element (PPCS). HESS lists HighlyReliable/Autonomous Deep-Space Cryogenic Refueling Systems as one of its themes, and identifies the technologies of long-term storage, low-loss transfer, and effective management of cryogenic fuels as essential to this theme. PPCS indicates the need to support propellant depots and space vehicles with long duration storage of high energy propellants. Cryogenic propellants would fill this role provided long-term storage technologies can be developed. PPCS also identifies oxygen and hydrogen as core products of In-Situ Resource Utilization. Effective use of Lunar-produced hydrogen and oxygen for deep space missions will require transfer of propellant at L1 or other locations outside Earth's gravity well.

\section{Technologies}

Researchers over the years have categorized the technological issues of cryogenic fluid management under thematic elements. Figure 2 presents these elements as well as a cartoon illustration representing the key concepts underlying them. The elements of importance to deep space cryogenic refueling likely to require flight testing to understand will be discussed in turn in the paragraphs below.

\section{A. Long-Term Storage}

Use of cryogenic propellants in deep space will require the development of long-term storage technologies. Passive storage techniques such as multilayer insulation and vapor cooled shields are reasonably well developed, but always involve some degree of liquid loss. Active storage techniques such as Zero Boil-off use high efficiency cryocoolers to remove environmental heating before liquid boiling can occur. ${ }^{8}$ These systems are capable of preserving liquid cryogens for the lifetime of the cryocooler. System trades have shown weight advantages to active storage systems over passive systems in as little as seven days. ${ }^{9}$ Ground test data applicability is good for all storage technology issues except for the issue of thermal stratification in a low gravity environment.

\section{B. Pressure Control}

Pressure control systems are vital to mission success and crew safety. Technologies have been developed for Saturn and Centaur ${ }^{6,7}$ but require large amounts of propellant if done repetitively. More sophisticated thermodynamic vent system techniques (which sacrifice a small portion of the stored liquid to cool the rest) in conjunction with de-stratification mixing will conserve propellants. ${ }^{10}$ However, low-g testing is highly desirable to evaluate the effects of low-g heat transfer, thermodynamics and fluid dynamics on destratification and mixing time.

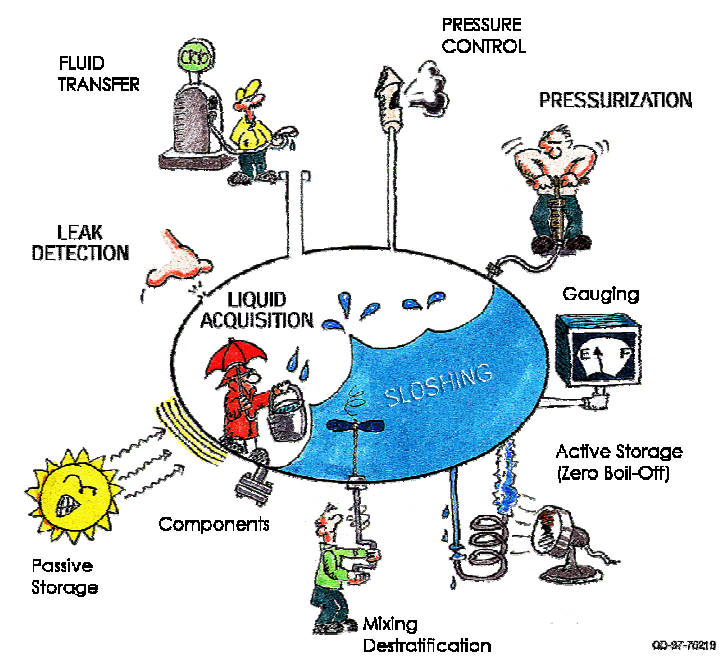

Figure 2.- The Cartoon Guide to Cryogenic Fluid Management Illustrating Key Concepts in Iconic Form 


\section{Mass Gauging}

Accurate measurement of propellant quantities is also essential to deep space missions. The current methods for measuring on-orbit propellant mass involve settling the propellant and measuring the liquid level, simply creating an inventory of propellant use rates, or utilizing an analytically-intensive Pressure-Volume-Temperature (PVT) gas law method. However, none of these options appear capable of the measurement accuracy goal of $1 \% .{ }^{11}$ Several new concepts are under investigation. Most of these concepts will require low-g testing.

\section{Liquid Acquisition}

The propulsion systems of most vehicles require single-phase propellant delivery. During the high acceleration engine thrust periods, single-phase expulsion is accomplished simply. However, in low gravity where liquid position is unknown, withdrawing only liquid becomes a challenge. Many deep space vehicles rely on special equipment know as Liquid Acquisition Devices (LAD). ${ }^{12}$ One common LAD is a screen channel device. Screen channel devices are typically metal channels, usually either a rectangular or triangular cross-section. One side of the channel has multiple openings covered with a tightly woven screen. As pressurized outflow or expulsion begins in reduced gravity, surface tension forces within the screen block the outflow of vapor and allow the passage of liquid as propellant. The channels are positioned so that one or more are always in contact with the liquid along the tank wall, independent of the liquid-vapor positions. Storable propellant screen channel LADs are state of the art, but LADs for cryogenic propellants will require study. Ground testing with representative LAD flow channels is needed. In addition, zero-g thermo-dynamics and heat transfer significantly complicate LAD design and performance. Therefore, orbital testing is likely to be required, although the risk is less with LO2 than with LH2.

\section{E. Fluid Transfer}

During a normal gravity transfer, a top vent is kept open to let out the vapor generated during the transfer process, thereby maintaining a low tank pressure. If the same approach is used in low gravity, the ullage gas may never vent. Instead of venting vapor, large amounts of liquid may be dumped overboard. If liquid is vented from one side, and vapor from the other side, of a non-propulsive vent, the spacecraft may tumble out of control. The spacecraft can be placed in an artificial gravity field by continuous thruster firing to position the ullage at a vent opening, but this may require dedicated thrusters and additional propellant. In places, such as a depot based at a space station, thrusting may be impractical due to large system size. ${ }^{1-2,13}$ One promising concept for propellants that can be pressurized with their own vapor (such as oxygen and hydrogen) is a procedure known as no-vent fill. ${ }^{12,13}$ This procedure uses liquid subcooling to re-condense vapor back into the incoming liquid. For tanks, which are warm and dry, a chilldown procedure is used to remove wall energy and a sacrificial quantity of cryogen is vented overboard as vapor prior to the start of the transfer. Space venting can also be used to remove non-condensable pressurant such as helium from tanks which are burned to depletion, prior to the start of the transfer process. The cryogen transfer operation involves complex thermodynamics, heat transfer and fluid dynamics that are strongly affected by zero-g environments. Therefore, an orbital demonstration is likely to be required.

\section{Technology Maturation}

Recent estimates of technical metrics for on-orbit cryogenic depots have been prepared for the NASA space architect by a panel of NASA cryogenic experts (including the author and several research team members). Estimated technical metrics are listed as numerical values for performance goals as follows:

- Storage with boil-off, \% losses/mo. $3 \%$

- Zero boil-off storage duration $5 \mathrm{yr}$

- Zero-g pressure control $0.5 \mathrm{psi}$

- Liquid acquisition device expulsion efficiency $\quad 98 \%$

- Zero-g mass gauging accuracy $1 \%$

- Cryogenic transfer efficiency $\quad 92 \%$ 
Candidate technologies capable of achieving these goals were selected for each technology element. Each candidate technologies was assessed for the following: Technological Maturity as a number rating on the Technological Readiness Level (TRL) scale in table 1 (summarized from reference 32); The most recent research in 1-G; Issues of Low Gravity which cannot be resolved by 1-G research; and the desirability of conducting flight tests to resolve these issues. Table 2 summarizes the findings of these assessments.

TABLE 1.-TECHNOLOGY READINESS LEVELS SUMMARY

\begin{tabular}{|c|l|}
\hline TRL 1 & Basic principles observed and reported \\
\hline TRL 2 & Technology concept and/or application formulated \\
\hline TRL 3 & Analytical and experimental critical function and/or characteristic proof-of-concept \\
\hline TRL 4 & Component and/or breadboard validation in laboratory environment \\
\hline TRL 5 & Component and/or breadboard validation in relevant environment \\
\hline TRL 6 & System/subsystem model or prototype demonstration in a relevant environment (ground or space) \\
\hline TRL 7 & System prototype demonstration in a space environment \\
\hline TRL 8 & Actual system completed and "flight qualified" through test and demonstration (ground or space) \\
\hline TRL 9 & Actual system "flight proven" through successful mission operations \\
\hline
\end{tabular}

TABLE 2.-FLIGHT TESTING REQUIREMENTS OF CFM TECHNOLOGIES

\begin{tabular}{|c|c|c|c|c|}
\hline $\begin{array}{l}\text { CFM } \\
\text { TECHNOLOGY } \\
\text { ELEMENT }\end{array}$ & $\begin{array}{l}\text { CURRENT } \\
\text { TRL }\end{array}$ & $\begin{array}{l}\text { PAST 1-G } \\
\text { ACCOMPLISHMENTS }\end{array}$ & LOW-G ISSUES & $\begin{array}{l}\text { FLIGHT } \\
\text { TESTING }\end{array}$ \\
\hline $\begin{array}{l}\text { PASSIVE } \\
\text { STORAGE- }\end{array}$ & 5 & $\begin{array}{l}\text { *3\% Loss/month Demonstrated } \\
\text { with Large Scale LH2 Test }{ }^{8}\end{array}$ & $\begin{array}{l}\text { Low-g thermal stratification } \\
\text { effects unknown }\end{array}$ & $\begin{array}{l}\text { Highly desirable } \\
\text { for stratification }\end{array}$ \\
\hline $\begin{array}{l}\text { ACTIVE STORAGE } \\
\text { (ZERO BOIL-OFF) }\end{array}$ & $\begin{array}{l}4 \mathrm{LO} 2 / \mathrm{CH} 4 \\
3 \mathrm{LH} 2\end{array}$ & $\begin{array}{l}* \text { Subscale demo with LN2 } \\
\text { and } 10 \mathrm{~W} \text { at } 97 \mathrm{~K} \text { cryocooler } \\
* \text { Large scale demo with } \\
\text { commercial cryocooler }^{9}\end{array}$ & $\begin{array}{l}\text { Low-g thermal stratification } \\
\text { effects unknown }\end{array}$ & $\begin{array}{l}\text { Highly desirable } \\
\text { for stratification }\end{array}$ \\
\hline $\begin{array}{l}\text { PRESSURE } \\
\text { CONTROL }\end{array}$ & 4 & $\begin{array}{l}\text { * Large scale demo of } \\
\text { thermodynamic vent system } \\
\text { (TVS) with spray bar } \\
\text { * Subscale test of TVS with } \\
\text { axial jet mixer }\end{array}$ & $\begin{array}{l}\text { Low-g heat transfer and fluid } \\
\text { dynamics effects mixing, de- } \\
\text { stratification and cycle rate }\end{array}$ & Highly desirable \\
\hline MASS GAUGING & 3 & $\begin{array}{l}* \text { Component testing with } \\
\text { simulant fluids, LN2 and } \\
\text { limited LH2 } 2^{11}\end{array}$ & $\begin{array}{l}\text { Some concepts strongly } \\
\text { effected by low-g heat transfer } \\
\text { and fluid behavior }\end{array}$ & Highly desirable \\
\hline $\begin{array}{l}\text { LIQUID } \\
\text { ACQUISITION }\end{array}$ & 3 & $\begin{array}{l}* \text { Bubble point testing with } \\
\text { LN2 }{ }^{12} \\
* \text { Historical data }(1960 \text { 's })\end{array}$ & $\begin{array}{l}\text { Low-g heat transfer } \\
\text { significantly effect LAD } \\
\text { performance }\end{array}$ & Required \\
\hline FLUID TRANSFER & 3 & $\begin{array}{l}* \text { Subscale demo of chill/no } \\
\text { vent fill testing }{ }^{2}\end{array}$ & $\begin{array}{l}\text { Transfer operation strongly } \\
\text { effected by low-g }\end{array}$ & Required \\
\hline
\end{tabular}

\section{Past Flight Experiment Experience}

Technologists have relied on flight tests to develop cryogenic fluid systems since the beginning of space travel. Drop tower, ${ }^{3}$ sounding rocket flights ${ }^{4}$ and subscale experiments carried on the Mercury missions ${ }^{5}$ provided vital information for the design of the Saturn IV and Centaur cryogenic upper stages. Information from these experiments and the subsequent full-scale demonstration flights ${ }^{6-7}$ successfully addressed the issues of propellant slosh, settling, and short-term storage/pressure control.

More recent flight experiments have proved valuable in understanding the behavior of fluids in low gravity. Notable experiments include: Storable Fluid Management Device (SFMD)/Fluid Acquisition and Resupply Experiment (FARE), which used a common set of hardware to explore several different transfer schemes; ${ }^{14-17}$ Tank Pressure Control Experiment (TPCE) ${ }^{18-22}$ which examined pressure control and tank mixing; and Vented Tank Resupply Experiment (VTRE), ${ }^{23}$ which looked at a vane device to separate gas and liquid during transfer. The super fluid on-orbit transfer (SHOOT) flight demonstration, ${ }^{24}$ was very successful in moving superfluid helium from tank 


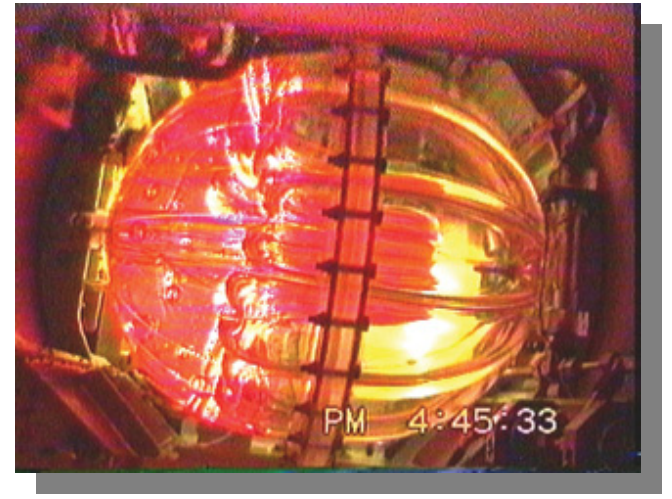

Figure 3.-Vented Tank Resupply Experiment during inflow, exhibiting center post fluid collection phenomena; predicted but unseen until VTRE flight.

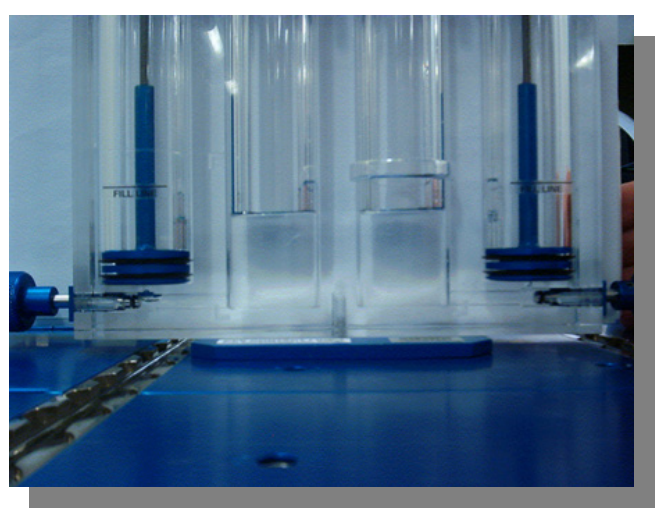

Figure 4.-Capillary Flow Experiment (CFE) hardware successfully launched to the International Space Station on a Proton with the current station crew.

to tank on-orbit. However, its reliance on the unique properties of superfluid helium make application of its results to other fluids difficult.

Past Attempts to move directly to TRL 6-7 experiments have proved costly. The Cryogenic On-Orbit Liquid Depot Supply Acquisition and Transfer experiment (COLD-SAT) ${ }^{25-27}$ was designed to support the Space Exploration Initiative by maturing key technologies to TRL 6. It was based on using a dedicated spacecraft filled with liquid hydrogen as the experiment platform. The concept was only carried through preliminary design but the Non-Advocate Review at the end of the COLD-SAT estimated the cost at about $\$ 200$ million.

A study of a low-cost sounding rocket alternative to COLD-SAT was initiated, ${ }^{28}$ but this was terminated at phase A due to a refocusing of the agency on earth to orbit transportation. Preparations for this sounding rocket effort were used by the GRC Microgravity Science Division to prepare several sounding rocket experiments of their own. Both the Spread Across Liquids (SAL) ${ }^{29}$ and Extensional Rheology Experiment (ERE) ${ }^{30}$ sounding rocket experiments are successful examples.

The Columbia tragedy has forced extreme innovation in the design of long-term microgravity experiments. NASA has responded with several very small-scale experiments that can be taken up on Proton launches with the space station crew. The Capillary Flow Experiment $(\mathrm{CFE})^{31}$ is a good example of this, having recently been launched to the station. The experiment is not yet complete, but went from concept to flight hardware in under a year.

\section{Approach and Methodology}

In response to a call for NASA led proposals a design team is being assembled to investigate low-cost experiments to mature the technologies of deep space cryogenic refueling. Composition of the team is as follows.

- Glenn Research Center (GRC) will lead this effort. GRC Propellant Management Experts will provide core technology information as well as findings from their Power, Propulsion and Chemical Systems research efforts. GRC Flight hardware experts will provide insights from numerous flight experiments including Shuttle Based (TPCE, VTRE), Space Station (CTE), Sounding Rocket (SAL, ERE), KC-135 and Drop Tower.

- Goddard Space Flight Center (GSFC) will provide input from the SHOOT flight experiment as well as shuttle integration information from their shuttle small payloads group and sounding rocket experience from their Wallops Island Flight Facility.

- Marshall Space Flight Center (MSFC) will provide findings from their High Energy Space Systems propellant technology maturation efforts as well as their flight experiment experience from FARE I, FARE II and $\mathrm{KC} 135$ research efforts.

- Johnson Space Center (JSC) will provide their expertise from Auxiliary Propulsion feed systems and NonToxic OMS efforts. 
- Kennedy Space Center (KSC) will provide insight from their lunar surface systems study.

- Langley Research Center (LaRC) will provide insight from their advanced systems RASC studies.

- Ames Research Center (ARC) will provide insight on thermal protection systems and high performance cryocoolers.

- Industry partners will be selected from existing Performance Based Contractors, to augment the research team with specialized knowledge of research needs.

- Industry partners will also be selected from respondents to a GRC Request For Quotation issued in May 2004 to augment the effort with additional specialized knowledge.

The design team intends to use their extensive experience in flight experiments to design low-cost experiments to mature core refueling technologies to TRL 5-6.

During Phase I, the NASA team personnel and their industry partners will prepare a white paper for each of the core deep-space cryogenic refueling technologies. The white papers will 1.) discuss the key fluid and thermal effects that require low-g experimentation and 2.) estimate the low-g duration required to address each effect. Close ties will be maintained with ground-based efforts under the Power, Propulsion, and Chemical Systems and High Energy Space Systems.

The team will investigate all potential flight opportunities. These include sounding rockets, International Space Station, low-cost free flying spacecraft and re-flight of existing Shuttle-based experiments. An inventory of available hardware from previous low-g experiments will be listed and their present condition and their potential for reflight identified.

Finally, the team will convene a panel of 10 to 12 technical experts to review all of this information-white papers, ESR\&T mission requirements, flight opportunities and inventory list. After the review, the panel will meet to rank the technologies on the basis of technical need, cost and return on investment, flight platform availability and ability of the flight platform to accommodate multiple key technology investigations. Based on the ranking, the panel will select two to four potential experiments. These results will be formally presented to ESR\&T management for their review and is the key deliverable from the Phase 1 effort of the proposed project.

During Phase II, a lead investigator will be chosen for each of the experiments proposed in Phase 1 and will be chartered (within the proposal budget constraints) to form a preliminary design team. The lead investigator for each experiment will:

- Prepare concept of operation that investigates the key issues on the designated experiment platform

- Assess cost of proposed experiment

- Assess ability to design hardware to conduct proposed experiment including long lead items, availability of hardware (off-the-shelf, custom manufacture, or development items)

- Assess availability of designated platform

- Assess level of technology readiness after completion of experiment

- Identify further experimentation required to mature core technologies to mission hardware

Near the end of the Phase 2 effort, a panel of 10 to 12 technical experts will convene to review the preliminary designs. The panel will review total cost, risk assessment, return on investment and technical merit. Based on their review, the panel will rank the proposals in priority order for consideration in the next round of ESR\&T flight experiment opportunities. A final report will be presented to ESR\&T management.

It is expected that three experimental efforts will emerge. One possible experiment could be a sounding rocket campaign (similar to ERE) with cryogens to study liquid acquisition, mass gauging and low gravity cryogenic transfer. The sounding rocket approach will yield sufficient low-g duration to investigate several key elements of a propellant management system in an economical flight experiment. Another could be a very small scale system using inert simulants in a clear tank flown to the Space Station on a Soyuz or Progress (like CFE) to study low-g stratification effects on long term storage. Yet a third could be a re-flight of the SHOOT hardware with normal helium or neon as a shuttle experiment or a Free Flying Satellite with liquid hydrogen. In order for the SHOOT reflight to be successful, it will need to address the availability of Shuttle payload space. 


\section{Summary}

Although the fields and goals of cryogenic fluid management for deep space refueling are well understood much remains to develop and prove out the technology in the real environment of space. NASA has assembled an experienced team to "flesh out" the development pathway and identify problems which can be tackled in the near term with the resources available. Although the ultimate proof-of-concept will probably still require flight

demonstration the scope and complexity of that flight demonstration can be reduced by up-front work now. The NASA team intends to use their extensive experience in flight experiments to achieve this goal.

\section{References}

1. Chato, D.J., "Technologies for Refueling Spacecraft On-Orbit” AIAA 2000-5107, September 2000.

2. Chato, D.J., "Cryogenic Transfer Options For Exploration Missions," AIAA 91-354, September 1991.

3. Otto, E.W., "Static and Dynamic Behavior of the Liquid-Vapor Interface During Weightlessness," Chemical Engineering Progress Vol. 62 No. 611966.

4. Knoll, R.H., Smolak, G.R., and Numamaker, R.R. "Weightlessness Experiments with Liquid Hydrogen in Aerobee Sounding Rockets; Uniform Radiant Heat Addition-Flight 1.” NASA TM X-484 June 1962.

5. Petrash, D.A. Nussle, R.C. and Otto E.W. "Effect of Acceleration Disturbances Encountered on the MA-7 Spacecraft on the Liquid-Vapor Interface in a Baffled Tank During Weightlessness." NASA TN D-1577, 1963.

6. Anon. "Evaluation of AS-203 Low Gravity Orbital Experiment." Chrysler Corporation January 1967.

7. Lacovic, Raymond F., et al. "Management of Cryogenic Propellants in a Full-Scale Orbiting Space Vehicle." NASA TN D-4571, May 1968.

8. Hastings, L.J. et al. "An Overview of NASA Efforts on Zero Boiloff Storage of Cryogenic Propellants." Space Cryogenics Workshop, July 2001.

9. Plachta, D.W. and Kittel. P. "An Updated Zero Boil-off Cryogenic Propellant Storage Analysis Applied to Upper Stages or Depots in a LEO Environment." NASA/TM 2003-211691.

10. Aydelott, J.C., Carney, M.J., and Hochstein, J.I. "NASA Lewis Research Center Low-gravity Fluid Management Technology Program." NASA TM-87145, November 1985.

11. Van Dresar, N.T., "An Uncertainty Analysis of the PVT Gauging Method Applied to Sub-critical Cryogenic Propellant Tank." Cryogenics Vol. 442004.

12. Chato, D.J., and Kudlac, M.T., "Screen Channel Liquid Acquisition Devices for Cryogenic Propellants," AIAA 2002-3983, July 2002.

13. Chato, D.J., et al. "Cryogenic Fluid Management Technologies for the Space Launch Initiative," IAC-02-V.5.05, October 2002.

14. Kirkland, Z. and Tegart, J., "On-Orbit Propellant Resupply Demonstration,” AIAA 84-1342, June 1984.

15. Tegart, J. and Kirkland, Z., "On-Orbit Propellant Resupply Demonstration-Flight Test Results," AIAA 85-1233, July 1985.

16. Dominick, S. and Driscoll, S., "Fluid Acquisition and Resupply Experiment (FARE I) Flight Results," AIAA 93-2424, June 1993.

17. Dominick, S. and Tegart, J., "Orbital Test Results of a Vaned Liquid Acquisition Device," AIAA 94-3027, June 1994.

18. Bentz, M.D., et al. “Tank Pressure Control Experiment-A Low-g Mixing Investigation,” AIAA 90-2376.

19. Bentz, Michael D., "Tank pressure control in low gravity by jet mixing," NASA-CR-191012, March 1993.

20. Bentz, M.D., Knoll, R.H., Hasan, M.M., Lin, C.S., "Low-g fluid mixing-Further results from the Tank Pressure Control Experiment," AIAA PAPER 93-2423, June 1993.

21. Hasan, Mohammad M., Lin, Chin S., Knoll, Richard H., and Bentz, Michael D., "Tank Pressure Control Experiment: Thermal Phenomena," NASA TP 3564, March 1996.

22. Bentz, Michael D. et al., "Tank Pressure Control Experiment - Results of three space flights," AIAA Paper 972816, July 1997.

23. Chato, D.J. and Martin, T.A.., "Vented Tank Resupply Experiment-Flight Test Results," AIAA 97-2815, July 1997. 
24. DiPirro, M., Shirron, P., and Tuttle, J., "On-Orbit Superfluid Transfer: Preliminary Results from the SHOOT Flight Demonstration." Cryogenics v.34 n.5, 1994.

25. Bailey, W.J. et al., "Cryogenic On-Orbit Liquid Depot Storage, Acquisition and Transfer Satellite (COLD-SAT) Feasibility Studies,” Martin Marietta Space Systems Co., NASA CR 185247, June 1990.

26. Schuster, J.R., Russ, E.J., and Wachter, J.P., "Cryogenic On-Orbit Liquid Depot Storage, and Transfer Satellite (COLD-SAT)" General Dynamics Space systems Division and Ford Aerospace Space Systems Division, NASA CR-185249, July 1990.

27. Rybak, S.C., et al., "Feasibility Study for a Cryogenic On-Orbit Liquid Depot-Storage, Acquisition and Transfer (COLD-SAT) Satellite,” Ball Aerospace Systems Group, NASA CR-185248, August 1990.

28. Chato, D.J., and Taylor W.J., "Small Experiments for the Maturation of Orbital Cryogenic Transfer Technologies," NASA Technical Memorandum 1055849, August 1992.

29. Ross, H.D., Miller, F.J., "Fluid Management of and Flame Spread Across Liquid Pools" in Sixth International Microgravity Combustion Workshop, NASA/CP-2001-210826, May 2001.

30. Mckinley, Gareth H., Anna, Shelley L. "The Evolution of Tensile Stresses in Uniaxial Elongational Flows of Dilute Polymer Solutions Subjected to a Known Preshear History." In Proceedings of the Fifth Microgravity Fluid Physics and Transport Phenomena Conference, NASA CP-2000-210470, December 2000.

31. May 2004 Private communication with John J. Caruso, former CFE project manager.

32. Human and Robotic Technology Formulation Plan Version 5.1 July 29, 2004 (amended September 13, 2004) available at http://exploration.nasa.gov/documents/nova_29july04b.pdf 


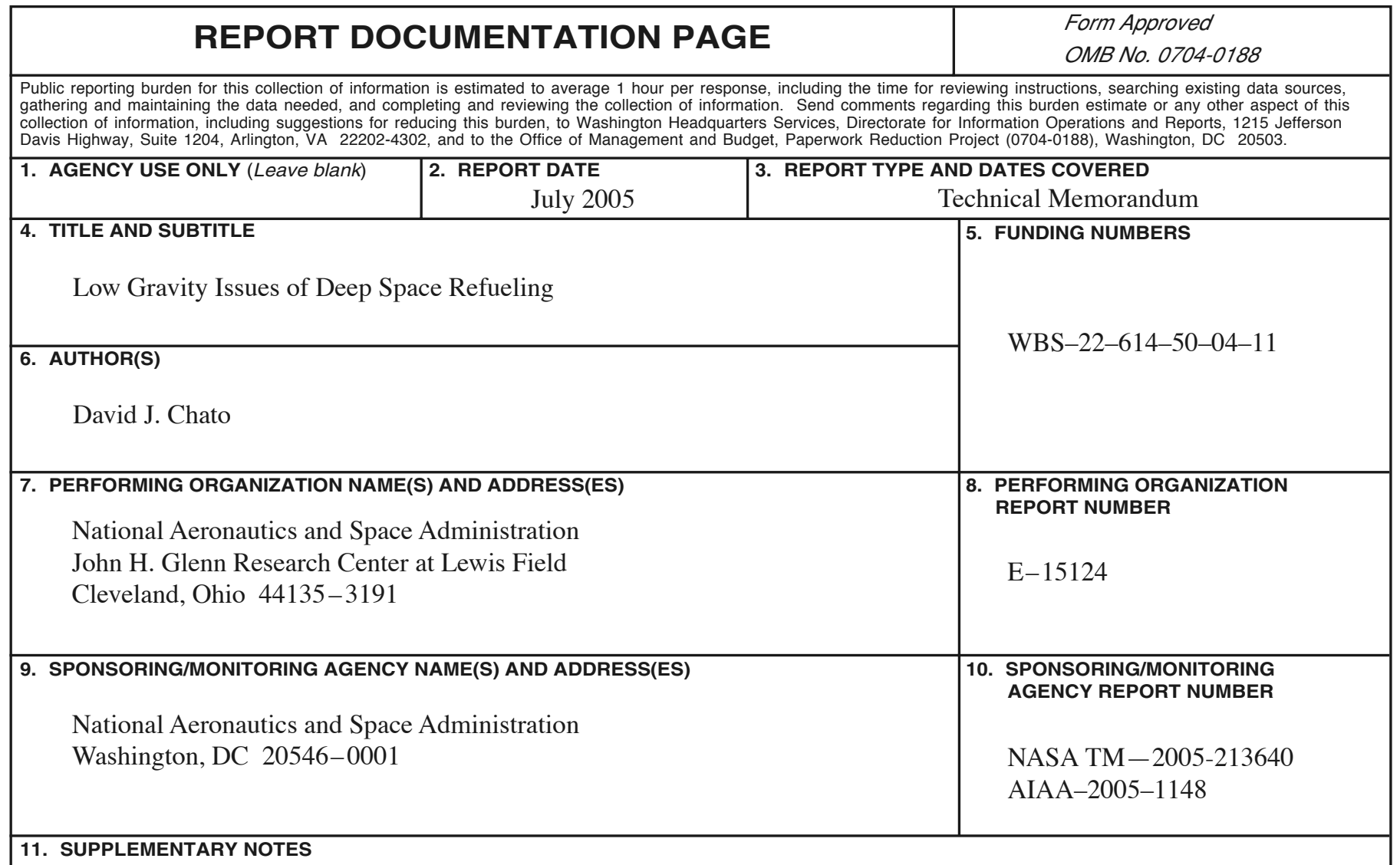

Prepared for the 43rd Aerospace Sciences Meeting and Exhibit sponsored by the American Institute of Aeronautics and Astronautics, Reno, Nevada, January 10-13, 2005. Responsible person, David J. Chato, organization code RTP, 216-977-7488.

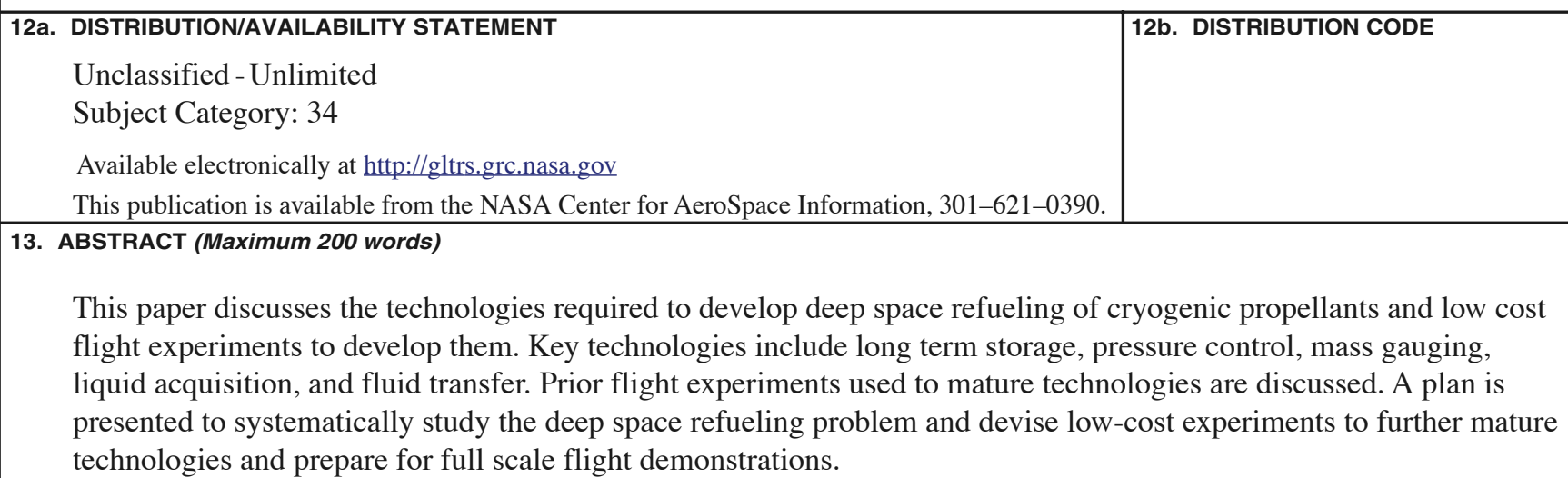
technologies and prepare for full scale flight demonstrations.

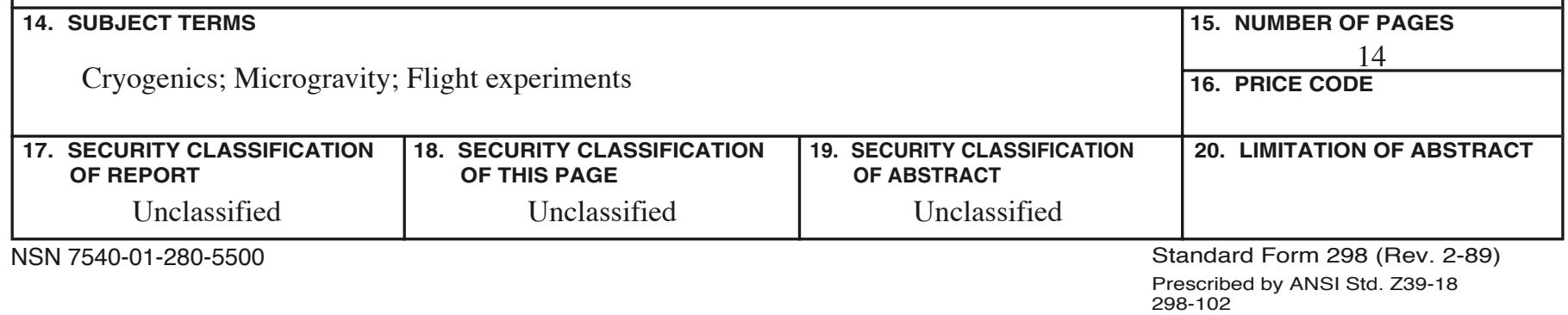



